\title{
Evaluation of sensory and biochemical changes in freshwater catfish stored under vacuum and different modified atmospheres.
}

\begin{abstract}
The present study was carried out to compare the influence of six different packaging atmospheres (air, vacuum and MAPs including 5\% O2 + 40\% CO2 + 55\% N2, 5\% O2+60\% $\mathrm{CO} 2+35 \% \mathrm{~N} 2,5 \% \mathrm{O} 2+80 \% \mathrm{CO} 2+15 \% \mathrm{~N} 2$ and $100 \% \mathrm{CO} 2)$ on the biochemical and sensory attributes of freshwater catfish fillets stored at $4{ }^{\circ} \mathrm{C}$. Fillets were monitored for biochemical parameters ( $\mathrm{pH}$, total volatile bases nitrogen (TVBN), lipid oxidation) and sensory attributes for 21 days. Proximate and fatty acid composition were also determined in fresh fillets. The sensory quality of all fillets was acceptable during the first $13 \pm 1$ days of storage in air, $16 \pm 1$ days of storage in vacuum and MAP1, $18 \pm 1$ days of storage in MAP2 and $20 \pm 1$ days of storage in MAP3. The overall sensory scores for fillets which were packed under $100 \% \mathrm{CO} 2$ were higher than the acceptable limit at the end of storage. It was found that fillets consisted of $5.71 \mathrm{~g}$ lipid per $100 \mathrm{~g}$ which is susceptible to oxidation due to the high amount of unsaturated fatty acids $(63.86 \%)$ versus saturated fatty acids $(31.14 \%)$. Vacuum packed and $100 \%$ CO2 fillets showed the lowest TBARS values while air-stored samples showed the highest TBA values. TVBN increased negligibly during storage in all treatments and never exceeded the acceptability limit ( $35 \mathrm{mg} \mathrm{N}$ per $100 \mathrm{~g}$ ). It can be concluded that $100 \%$ $\mathrm{CO} 2$ was the best evaluated atmosphere for storage of catfish fillets at $4{ }^{\circ} \mathrm{C}$ with superior biochemical and sensory attributes.
\end{abstract}

Keyword: Sensory; Biochemical changes; Freshwater catfish; Vacuum; Modified atmospheres. 